\title{
Analysis of the influence of sustainable development factors on the state of the housing function in a large city
}

\author{
Luiza Seferyan ${ }^{1 *}$, Bagavdin Magomedov $^{2}$, Pari Shuaipova ${ }^{2}$, Marina Nikulina ${ }^{2}$, Anna \\ Shevtsova ${ }^{3}$ \\ ${ }^{1}$ Rostov-on-Don Construction College, 344082, Rostov-on-Don, Russia \\ ${ }^{2}$ Rostov Institute (Branch) of the All-Russian State University of Justice, (Russian Law Academy of \\ the Ministry of Justice of Russia), 344000, Rostov-on-Don, Russia \\ ${ }^{3}$ Don State Technical University, 344000, Rostov-on-Don, Russia
}

\begin{abstract}
The authors of the article consider the sustainable development of the housing stock of a large city from the standpoint of four factors: increasing the energy efficiency of buildings under construction and renovation; overhaul of apartment buildings, taking into account the requirements for their energy efficiency; the choice between construction and reconstruction according to the resource costs criterion; management of the housing stock resource supply based on the requirements for comfortable living of owners and improving the quality of services provided in the field of housing and utilities infrastructure (hereinafter HUI). According to the authors, it is necessary to use energy-saving modern building materials, products and structures and to assess the life cycle of buildings when choosing organizational and technical solutions for the demolition or reconstruction of buildings for the sustainable development of the housing stock.
\end{abstract}

\section{Introduction}

Modern society is developed according to the principles of sustainable development, the main ones of which are: improving human living conditions in terms of environmental impact within the economic capacity of the biosphere; satisfaction of needs in the present without prejudice to future generations $[1,2]$. The leading form of territorial and socioecological-economic organization of modern society is the city as a system. At present, the problem of the cities' sustainability is quite acute in Russian conditions. In the last 20 years in Russia, there has been a twofold dynamic of the situation development: on the one hand, the humanization of the urban environment is developing by improving the external aesthetic, practical and moral characteristics of buildings and structures, on the other hand, the non-scale of architecture and man in large Russian cities, as well as the inability of the

\footnotetext{
${ }^{*}$ Corresponding author: Luiza.seferyan@mail.ru
} 
existing general plans to be implemented in practice due to the rapid change of political and momentary utilitarian-practical conditions. The regional settlement schemes that have taken shape in Russia, as a rule, correspond to the idealized ecological scheme [3, 4]. At the same time, no attention is paid to such important issues as environmental pollution by industrial production and consumption waste, construction scrap obtained from dismantling buildings, etc., which lead to a decrease in the usable land area, and also require huge storage costs for burial, waste disposal, etc. This is especially true for large cities in which constant processes of construction, reconstruction and overhaul of buildings are carried out. The priority direction of modernization and the formation of an innovative economy is the development of human potential and a person as the main productive force of society. Therefore, this process should begin with the renewal of living conditions, education, health and culture of the population. One of the first places in this row is the housing issue providing citizens with modern, affordable, comfortable housing. In this regard, it becomes relevant to develop a conceptual framework for sustainable development of the housing stock. It is especially important to adopt organizational source and energy saving organizational and technical solutions in the development of programs for the sustainable development of the housing stock in large cities, when, when developing planning programs for new residential neighborhoods, it is necessary to make a reasonable choice between reconstruction of the existing buildings and construction of the new ones.

\section{Material and research methods}

As a rule, the modern classification of cities is based on the criterion of population size, that is, the city size. The lower border of the city (less than 10 thousand people) classifies cities as small. With an urban population of 50 to 100 thousand people, settlements are classified as medium-sized cities. The settlements with a population of over 100 thousand people are large. In total in the Russian Federation (RF) (according to the Federal State Statistics Service, based on the All-Russian Population Census, held from October 14 to October 25, 2010, in some places the census was carried out from April 1 to December 20, 2010) on January 012011 , there are 1099 cities, of which a third of cities with a population of 20 to 49.9 thousand people (Figure 1). The number of cities with a population of over 100 thousand people is 164 (15\% of the total). There are 11 million-plus cities. At the same time, the growth of the urban population has a positive trend. Thus, according to the latest census, the overall growth of the urban population in 2010 was about 15 million people, while the rural population decreased by 4.3 million people. The data was compiled by the authors based on information from the Federal State Statistics Service and are presented in the Table $[5,6]$.

The planned All-Russian Population Census was planned to be held from October 1 to 31, 2020, and the census in remote areas - from April 1 to December 20. However, due to the spread of COVID-19, it was decided to postpone the event to September, and later to October 2021.

The deadline for summing up the next preliminary results of the All-Russian Population Census is October 2021, by the end of 2022 the final results of the census will be summed up and officially published.

According to Table 1, it can be concluded that the population in the Russian Federation is shifting towards cities, thus, the problem of comfortable living is becoming more and more urgent. According to the authors, sustainable urban development is inextricably linked with the housing stock development. The factors influencing the sustainable development of the city housing stock are presented in this article. 


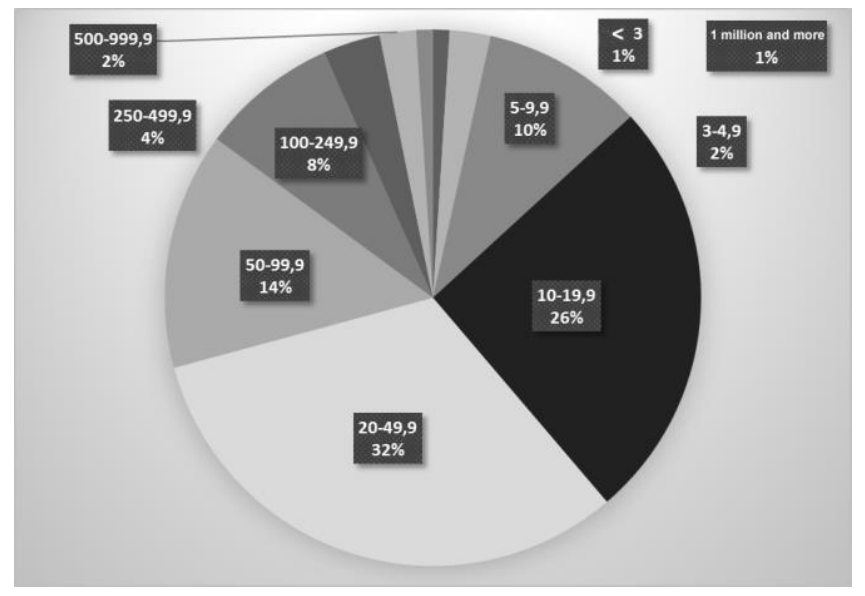

Fig. 1. Distribution of cities in the Russian Federation by population (formed by the author according to the FSSS data as of 01.01.2011)

Table 1. Total increase (decrease) in the resident population in the constituent entities of the Russian Federation in 2010

\begin{tabular}{|l|c|c|c|}
\hline $\begin{array}{c}\text { Population growth in the Russian } \\
\text { Federation }\end{array}$ & $\begin{array}{c}\text { All } \\
\text { population }\end{array}$ & Urban & Rural \\
\hline Russian Federation & 10530 & 14887 & -4357 \\
\hline Central Federal District & -3828 & 37808 & -41636 \\
\hline Northwestern Federal District & -25153 & -12938 & -12215 \\
\hline Southern Federal District & -1128 & -2232 & 1104 \\
\hline North Caucasian Federal District & 68039 & 41556 & 26483 \\
\hline Volga Federal District & -48455 & -24304 & -24151 \\
\hline Ural federal district & 25147 & -29508 & 54655 \\
\hline Siberian Federal District & 15617 & 18632 & -3015 \\
\hline Far Eastern Federal District & -19709 & -14127 & -5582 \\
\hline
\end{tabular}

\section{Research results and discussion}

The relevance and importance of identifying the factors of the cities' housing stock sustainable development, especially for the large ones (with a population of over 100 thousand people), is also due to the fact that the management of a large urban agglomeration should take into account both satisfaction in housing services, on the one hand, and the development of the construction industry, on which the construction of new, major repairs and reconstruction of existing buildings depends, on the other. The author identified the following factors:

1) Improving the energy efficiency of residential buildings.

According to Federal Law No. 261-FL, all designed, constructed and reconstructed buildings in the Russian Federation must have a high energy efficiency class. The rules for determining and assigning energy efficiency classes for multi-unit apartment buildings (hereinafter referred to as: MUAB), constituting the basis of the housing stock in a large 
city, are determined by the order of the Ministry of Construction of Russia "On approval of the Rules for determining the energy efficiency class of apartment buildings" No. 399/r dated June 6, 2016. Improving the energy efficiency of buildings is necessary at all stages of the life cycle, since when designing buildings, one of the criteria for evaluating design solutions, including the choice of building materials, along with the criteria for environmental safety, should be the total specific energy consumption for construction building, its operation (heating, repairs, etc.) for the entire estimated service life of this building and further disposal. At the same time, it is necessary to take into account the fact that the savings from choosing the most heat-saving building material in the end for the entire life cycle of a building with a short service life will be less than when choosing a less heat-saving, but at the same time less energy-intensive in production and more environmentally friendly, and with a long service life during the life cycle [7]. Thus, energy and resource conservation, improving the energy efficiency of buildings, is an important factor in the sustainable development of urban housing stock.

2) Development of overhaul MUAB programs taking into account the requirements for their energy efficiency.

This factor is associated both with the constantly growing wear and tear of building elements and engineering infrastructure, and with the emergence of requirements to increase the energy efficiency of buildings, as well as with the widespread implementation of capital repair programs. Despite the fact that many regulatory legal acts have been adopted and several pilot projects have been implemented to improve MUAB energy efficiency, many acute problems remain relevant and unresolved:

- government subsidies for MUAB energy efficiency programs;

- coordination and interconnection of MUAB overhaul and energy efficiency programs;

- provision to owners of MUAB premises in and managing organizations the possibility of MUAB concluding management contracts, including the conditions for increasing the energy efficiency of such houses;

- cancellation of the requirements of the Rules for the maintenance of common property in MUAB (RRRF No. 491) on a separate energy service agreement;

- an increase in the maximum term for concluding an agreement for the management of an apartment building in the event that energy service is included in it;

- revision of the legal regulations governing the Condominium Partnership (CP) operation. CP creation without membership and owners' liability for CP obligations [8].

MUAB construction, reconstruction and overhaul is necessary to be carried out with the use of modern resource and energy saving building materials, as well as the technologies for the production of construction and installation works [9, 10]. Development of overhaul MUAB programs taking into account the requirements for energy efficiency enables the state to motivate customer services for the construction of energy efficient buildings through preferential loans, co-financing, etc. There are many such incentives abroad, and they work. In Russia, all these incentives, without reference to the scale of energy efficiency criteria, are mainly spelled out in Law No. 261-FL. But they have not come into operation yet. The system of training multidisciplinary appraisers, similar to the foreign one, is practically absent in Russia. The introduction of energy efficiency classes does not (yet) provide buyers of new homes with any incentives for energy-efficient behavior, no preferences in tariffs or mortgages. However, incorporating building energy efficiency into capital renovation programs MUAB becomes an important factor in the sustainable development of housing stock.

3) A reasonable choice between the demolition of existing buildings and the construction of new ones, based on an assessment of the cost of energy and resources during their life cycle. 
The concept of the life cycle of both individual products (including building materials and structures) and buildings as a whole is currently very relevant. The life cycle of a building includes the following main stages: design, erection, operation, overhaul and disposal. The main share of energy consumption (up to $90 \%$ ) falls on the operation of buildings, in the process of building materials and structures' production about $8 \%$ is consumed, in the process of construction - about $2 \%$. From the standpoint of energy saving in housing construction, the leading role belongs to the stages of design and construction of a building, the final result of which is manifested in the socio-economic effect at the stage of operation of the building. Taking this factor into account, it is necessary to maintain a reasonable balance between the housing stock under construction, the existing housing stock and the renovated housing stock, as well as dilapidated and emergency ones subject to dismantling and disposal. Maintaining the balance of these components will ensure its sustainable development.

At the final stage of a building life cycle, it is necessary to make organizational and technical decisions on the feasibility of the buildings' construction redevelopment, taking into account energy and resource conservation. The main purpose of the reconstruction is to bring the object into a state that meets the customer's requirements by methods of architectural, functional and planning transformation.

Figure 2 shows the main periods of the life cycle of buildings with the distribution of costs for operation, reconstruction and the corresponding income received from the implementation of a set of works. Life cycle extension is represented by the area $\mathrm{Tu}^{\mathrm{r}}(\mathrm{VIII})$, which includes a set of works and costs for reconstruction with subsequent costs and income.
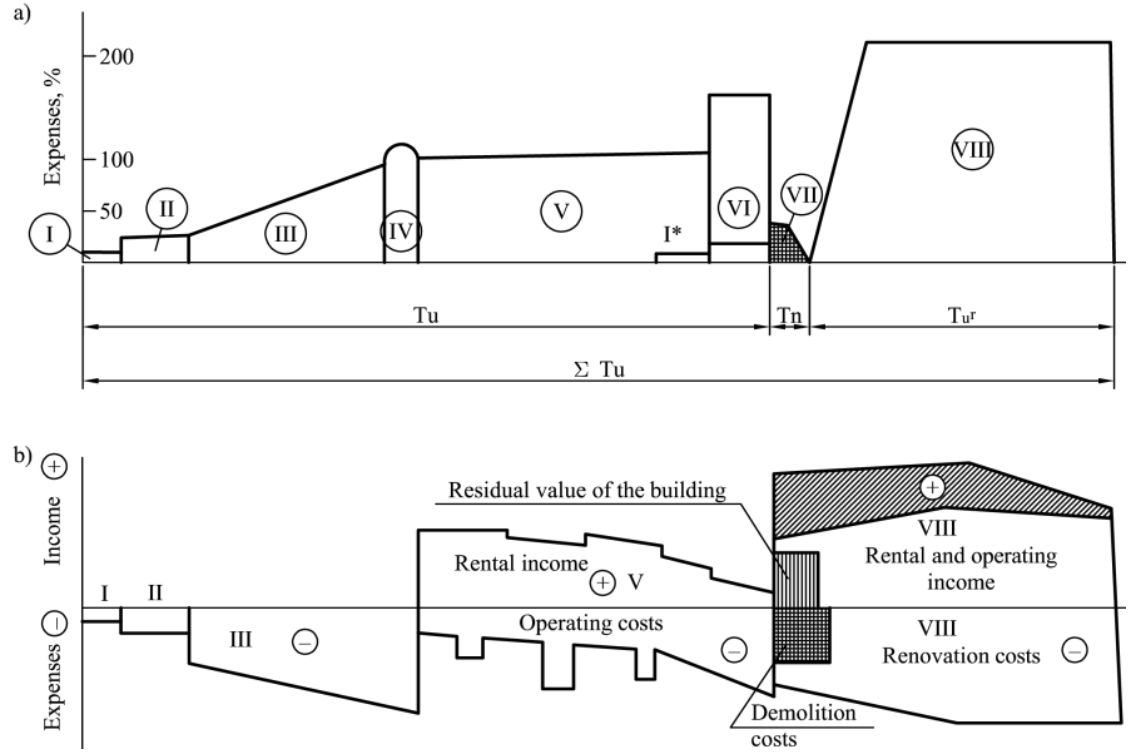

Fig. 2. Dynamics of the life cycle of buildings (a) and distribution of costs (b) when performing repair and restoration work and reconstruction

The most typical ratio dynamics of costs and received profit over time is shown in Fig. 2 (b), when, at a certain period (V), not only unprofitability is observed, but also the unsafe operation. This circumstance testifies to the need to make a decision on the demolition of the building and on the construction of a new one, on its reconstruction, providing qualitatively new technical and economic indicators, as well as on changing the functions of the building (transfer from residential to non-residential). This factor should be especially taken into account when developing the programs for the renovation and 
rehabilitation of residential neighborhoods. At the same time, it is extremely important to take into account and evaluate the environmental consequences of demolition of the existing buildings and construction of the new ones.

4) Management of the housing stock resource supply based on the requirements for comfortable living of the owners and improving the quality of services provided in the field of HUI.

The wider the scale of economic activity and the higher the rates of economic and social development of the regions, the greater the need for high-quality social security, i.e., in the high quality of social infrastructure services, a component of which is HUI. At the same time, great importance is attached to improving the quality of HUI services and the use of resources to meet consumer needs. Quality management system for providing consumers with HUI services realizes its goals through sectoral and territorial planning of HUI supply. A certain level of provision is constantly taken into account and the plans of enterprises and organizations are directed HUI region to achieve it. The main objectives of the quality management system HUI - development of forms and methods of quality management of consumer provision and satisfaction of needs for HUI services, based on the normative method, program-targeted, subject-oriented, etc. The management mechanism within the quality system in HUI in the region, can be represented as a process of interaction between the general and special subsystems, as well as the support subsystem. Variety of specific quality characteristics of service provision HUI, significantly complicates the choice of the assessment indicators' system.

Obviously, therefore, among the works devoted to this issue, there is no unified system in the qualitative assessment of the consumers provision in HUI. Based on the methodology for analyzing the quality of complex socio-economic processes, which include the process of providing consumers with HUI, the author came to the conclusion that the formation of indicators for assessing the quality of provision should be carried out taking into account a fairly complete reflection in them of the real processes occurring in the field of commodity circulation, the maximum possible coverage of the most significant properties, differentiation in the hierarchy of management and types of services, a combination of analytical and synthetic estimates [11]. HUM quality assurance plan is proposed to evaluate using the following indicators: service quality index HUI, quality indicators of HUI departments' specific elements, HUI resource utilization indicators, resource use of HUI reserves. At the same time, it is necessary to manage the resource supply of the housing stock not only on the basis of the managers and resource-supplying organizations' economic efficiency criterion, but also on the basis of the services and the requirements' quality for comfortable living of the owners [12].

\section{Conclusion}

Thus, taking into account the analysis carried out, the factors of sustainable development of the housing stock in a large city are identified. Taking these factors into account when developing the programs for development of the housing stock in large cities is a complex task, the solution of which is possible with the help of modern modeling tools: building simulation and optimization models, developing road maps and structural organizational as well as economic schemes. Work in this direction is extremely important and relevant in the modern world, moving along the trajectory of sustainable development. 


\section{References}

1. L.A. Seferyan, Formation of the socio-economic strategy of the city of Rostov-on-Don in the field of housing and utilities infrastructure, Materials of the I (IV) International scientific and practical conference, Stavropol, North Caucasus Federal University, part3, 58-61 (2012).

2. L.A. Seferyan, Journal "Izvestia RGSU", Rostov-on-Don 17, 49-55 (2013).

3. S.B. Yazyeva, L.A. Seferyan, L.A. Oparina, A.Y. Golubeva, Materials Science Forum 931, 883-888 (2018).

4. L.A. Seferyan, T.N. Kondrateva, V.E. Morozov, I.V. Leusenko, IOP Conference Series: Materials Science and Engineering 698 (5), 055004 (2019).

5. L.A. Seferyan, V.E. Chubarov, K.V. Chubarova, Modern architectural - planning, organizational, technological, constructive solutions at green roofing, CATPID 2020, IOP Conf. Series: Materials Science and Engineering 1083, 012049 (2021). doi:10.1088/1757-899X/1083/1/012049

6. L.A. Oparina, Theory and practice of technical, organizational and economic solutions: collection of scientific works 1, 53-58 (2015).

7. V.L. Adamyan, G.A. Sergeeva, L.A. Seferyan, N.Y. Gorlova, Development of technological measures to ensure the safety of production facilities in petrochemical industry, CATPID 2020, IOP Conf. Series: Materials Science and Engineering 1083, 012050 (2021). doi:10.1088/1757-899X/1083/1/012050.

8. S.V. Fedosov, V.E. Rumyantseva, S.V. Konovalov, V.I. Karavaev, Composite reinforcement as a method of increasing the durability of building constructions, collection: Effective building composites Scientific-practical conference for the 85th anniversary of the honored worker of science of Russia, academician RAASN, doctor of technical Sciences Bazhenov Yury Mikhailovich. Belgorod state technological University. V. G. Shukhov 700-710 (2015).

9. L.A. Seferyan, Factors based on ensuring the quality of services of consumers of housing in a market economy, International scientific-practical conference "Construction 2012", Rostov-on-Don, RSSU, 2012.

10. L.A. Seferyan, State support of the reform of the housing sector // "Information Resources Supply the Competition." M. 3, 254 - 256 (2010).

11. Organization of planning for the technical operation of dilapidated housing in the city of Rostov-on-Don. "Scientific Review" 24, 117-121 (2017).

12. Information on http://obozrenie.ucoz.ru/ Kiryanova A.A

13. S.G. Sheina, K.V. Chubarova, L.V. Girya, L.A. Seferyan, The Use of Information Technology in Territorial Planning of a Subject of the Russian Federation, CATPID2020, IOP Conf. Series: Materials Science and Engineering 913, 042025 (2020). doi:10.1088/1757-899X/913/4/042025 